\title{
25 AÑOS DE POLÍTICAS EUROPEAS EN EXTREMADURA: TURISMO RURAL Y MÉTODO LEADER
}

\author{
Ana Nieto Masot \\ Gema Cárdenas Alonso \\ Universidad de Extremadura
}

\section{RESUMEN}

Durante los últimos 25 años se vienen aplicando en las zonas rurales europeas, y más concretamente en Extremadura, unas estrategias territoriales bajo el conocido como Método LEADER con las que activar su desarrollo económico. Esto se lleva a cabo mediante la implantación de nuevas actividades, como el turismo rural, cuyo objetivo es mantener a la población y frenar los procesos emigratorios y el envejecimiento.

En este trabajo se analiza la evolución de las ayudas destinadas al turismo rural en Extremadura y se estudia su implantación territorial con unos indicadores de contexto, como son las inversiones y proyectos por superficie y población en los distintos Grupos de Acción Local, además de otras variables socioeconómicas y demográficas, con el fin de poder comprobar el éxito en sus objetivos iniciales.

Palabras clave: Método LEADER, Desarrollo Rural, turismo rural, Extremadura.

\section{5 years of European Policy in Extremadura: Rural Tourism and LEADER Method}

\section{ABSTRACT}

During the past 25 years, it has been applied in Europe's rural areas, and especially in Extremadura, territorial strategies through the LEADER Method in order to enable their economic development. This is by means of implementation of new activities as Rural Tourism is. The objective is to keep the population and slowing emigration processes and aging.

Recibido: 30 de noviembre de 2015

Devuelto para su revisión: 25 de abril de 2016

Aceptado: 13 de junio de 2016

Departamento de Arte y Ciencias del Territorio. Universidad de Extremadura. Avda. Universidad, s/n. 10071 (CÁCERES) España. E-mail: ananieto@unex.es, gemacardenas@unex.ex 
In this paper, the evolution of aids to Rural Tourism is studied, as well as its regional implementation with context indicators, such as investments and projects by area and population of Local Action Groups. Moreover, other socioeconomic and demographic variables are studied to verify the success of its initial objectives.

Keywords: LEADER Approach, Rural Development, Rural Tourism, Extremadura.

\section{INTRODUCCIÓN. EL MÉTODO LEADER}

Las zonas rurales europeas, desde la década de los 50, vienen sufriendo un proceso de deterioro económico y social, debido a las profundas transformaciones económicas y, muy en particular, las reestructuraciones que se realizan en el sector agrario. Pasaron de una agricultura de subsistencia a una agricultura que tuvo que volverse cada vez más competitiva y entraron en una dinámica de inversión y modernización que sólo algunas pudieron abordar con éxito. Como se menciona en la Agenda 2000, en las zonas agrarias "que no se han podido adaptar a estos cambios, donde se abandonan las actividades agropecuarias tradicionales, la población empieza a emigrar y es donde aparece una estructura social en declive". En estas zonas se produjo una reducción drástica de los activos agrarios, que emigraron masivamente a las zonas de concentración industrial. Como consecuencia de ello, se producirá una fuerte regresión demográfica y el envejecimiento de la población. La ausencia, además, de políticas públicas en el medio rural español (González, 2000), sumado a que las pocas existentes han sido escasas, discontinuas y desiguales (Alberdi, 2004, González Cabrera, 2004), no mitigó estos procesos de deterioro.

En oposición, en las zonas urbanas se desarrolló inicialmente, con fuerte impulso, una economía industrial y posteriormente de los servicios, ayudada con políticas públicas fuertes de concentración de inversiones (Méndez y Caravaca, 1996). Debido a estas circunstancias, se producirán importantes diferencias socioeconómicas entre las zonas rurales y las zonas urbanas, ya que éstas últimas se convierten en verdaderos núcleos generadores de empleo, actividades y riqueza, por la citada concentración de las inversiones productivas. A finales de los 70 y principios de los 80 , se unirán a los hechos anteriores la aparición de una crisis económica a escala mundial motivada por la caída del precio del petróleo en 1973 que volverá a modificar todos lo planteado hasta el momento. Estas zonas urbanas entran en regresión económica y por ello ya no pueden abarcar los excedentes agrarios del mundo rural.

Todas estas características coyunturales también se han producido en nuestra región de estudio, Extremadura. En los años 60 y 70, la región perdió alrededor de 800.000 activos agrarios que emigraron hacia zonas urbanas exteriores en busca de empleo, produciéndose como elemento coyuntural a la emigración de la población joven y sobre todo masculina, un proceso de feminización y envejecimiento de la población agraria. En las siguientes décadas, a partir de los años 80 , la población extremeña se ha mantenido y no se han producido los fenómenos migratorios masivos de décadas previas, pero se experimenta otra problemática, los espacios rurales menores (inferiores a 2.000 habitantes) presentan 
un crecimiento demográfico negativo producido por sus altas tasas de mortalidad, mínimas de natalidad y unos movimientos migratorios en favor de la emigración hacia espacios urbanos más dinámicos aunque sean dentro de la misma región extremeña (García y Nieto, 2015). El envejecimiento y el débil crecimiento natural de la población, a lo que se une la falta de oportunidades laborales, está condicionando al medio rural, convirtiéndose en un factor de repulsión de la población activa y joven de los municipios con una menor entidad poblacional (Nieto y Gurría, 2005). Estos núcleos menores, debido a la expulsión de población joven y su dinámica demográfica regresiva, muestran, además, el peligro de su desaparición en las próximas décadas.

Por ello, surge la necesidad de mantener a la población en las zonas rurales fundamentándose en el intento de equiparar sus características socioeconómicas con las de las urbanas y así poder frenar los procesos migratorios hacia las ciudades. Esta preocupación viene plasmada en documentos de la Unión Europea, como "El futuro del mundo rural"( 1986) y la Estrategia Territorial Europea (1999), iniciando con ellos el diseño de nuevas ayudas de desarrollo rural apoyadas en tres aspectos claves: igualar el nivel de vida de las zonas urbanas y rurales, favorecer la implantación de actividades productivas diversificadas potenciando los sectores industrial y servicios y frenar la despoblación y la decadencia de los espacios rurales (Cánoves et al, 2006).

Una de las vías para mejorar el nivel de vida de la población rural es potenciar un modelo de desarrollo basado en la práctica de la diversificación de actividades y en el que sus principales actores e iniciativas surjan del propio medio local. Desde esta perspectiva, el desarrollo de la actividad turística es y será un importante factor que puede contribuir al incremento del nivel de vida, al generar nuevas posibilidades de ingresos. El turismo y las diferentes actividades vinculadas a él no siempre deben sustituir a las actividades agrícolas, sino darse de manera complementaria (Loscertales, 1999).

De este modo, se necesitan cambios en el sector agrario, porque la evolución de la agricultura ha mostrado su incapacidad para el desarrollo de las áreas rurales (Majoral y Sánchez, 2001), hecho que ha obligado a plantear modelos tendentes a recuperar actividades abandonadas, crear otras que aprovechen las nuevas tecnologías y cambios en la demanda, estimular a los actores para llevarlas a cabo, y movilizar a estos actores en el contexto local con los instrumentos adecuados. La agricultura debe ampliar su función productiva tradicional, basada en la obtención de materias primas, ofreciendo servicios, vinculándose esta última función a la difusión de nuevas actividades económicas apoyadas, por un lado, en la puesta en valor de sus recursos patrimoniales, naturales y paisajísticos y, por otro, en la relevancia creciente que en estas sociedades adquiere el tiempo libre y, específicamente, la búsqueda de nuevos productos turísticos frente al denominado turismo de sol y playa. Se hace necesario utilizar estos cambios en las tendencias de consumo de las sociedades urbanas en las últimas décadas e introducir la explotación turística de estos espacios naturales como una actividad complementaria a la agraria y fomentar la coexistencia entre este aprovechamiento intensivo de los recursos agrarios como un escenario abierto a introducir nuevas prácticas de turismo rural y del turismo natural (Hernández y Rico, 2008).

A través de las ayudas al desarrollo rural se fomenta la viabilidad ambiental de las zonas rurales y de su explotación agraria, con el agricultor considerado como preservador de valores patrimoniales y paisajísticos (Carvalho y Fernándes, 2001), y la 
agricultura asume un papel multifuncional, con el turismo incluido, que trata de revalorizar a los elementos materiales desde los símbolos, afirmando el auto concepto de las poblaciones locales (Reis, 1998, García y Cebrián, 2008). La revalorización de la silvicultura, la reforestación con especies autóctonas, y por tanto la conservación de los paisajes autóctonos, permiten potenciar actividades ganaderas, forestales y cinegéticas. Aunque tradicionalmente estas actividades han estado vinculadas a la complementariedad de rentas agrícolas, el objetivo es integrarlas en una oferta más del turismo en espacio rural (Canovés et al, 2006). Por esta razón, conservación y desarrollo no pueden ser concebidos como conceptos antagónicos y su compatibilidad es esencial para dinamizar los recursos locales (Troitiño, 1993). El patrimonio -natural y cultural-, no es solo un conjunto de bienes objeto de inventario, sino que puede ser explotado, y las actuaciones dirigidas a su conservación y recuperación tienen un impacto económico. El territorio constituye el principal recurso de la actividad turística, además de ser soporte y escenario para la práctica de un turismo de carácter cultural o ambiental donde el paisaje rural constituye su factor primordial.

Por ello, el turismo rural se convierte en una actividad que puede complementar las rentas de los espacios profundamente afectados por la despoblación y la crisis del modelo productivo agrario tradicional (García y De la Calle, 2006), pero favorecido por el despegue espectacular de las nuevas inquietudes y necesidades de la población urbana: viajes de fin de semana o de corta duración a lugares tranquilos, con espacios poco transformados, con una rica oferta de gastronomía, rutas, enclaves y parajes naturales, fiestas y folklore tradicional, artesanía, etc. y de un turismo complementario que lo integre todo. Este hecho se puede encontrar en regiones como la extremeña, favorecida también gracias al desarrollo, en las últimas décadas, de las vías de comunicación y por la proximidad a núcleos urbanos como Madrid, Lisboa, Sevilla, Salamanca, Valladolid, etc.

Desde la Unión Europea se han realizado numerosas actuaciones en favor de modificar las economías de las zonas rurales, como las Reformas de los Fondos Estructurales de mediados de los años 80, los sucesivos cambios de la Política Agraria Común aumentando sus aportaciones a la diversificación de actividades y disminuyendo las ayudas directas a la producción, la aparición del concepto de desarrollo rural en la "Declaración de Cork"(1996) o el fomento de nuevas actuaciones de gestión pública local de abajo a arriba ("bottom - up") desde la creación de la Iniciativa LEADER I (1991).

En este trabajo se analiza una de las metodologías de la UE empleadas para fomentar el desarrollo socioeconómico de los espacios rurales, las Iniciativas LEADER y los programas PRODER y, más concretamente, sus inversiones en el sector turístico en la región extremeña. Surgen a principios de la década de los 90 del siglo pasado, como respuesta a los acuciantes problemas sociales, económicos y demográficos del medio rural europeo y con la pretensión de activar su potencial y mantener un nivel demográfico adecuado, diversificar la actividad económica, conservar el patrimonio, fomentar el uso de las nuevas tecnologías, etc. (Cebrián, 2003), mediante la puesta en marcha de una serie de proyectos, cofinanciados por los Fondos Estructurales europeos, las administraciones nacionales y agentes privados (sociales y económicos) (Nieto y Cárdenas, 2015). El objetivo de las ayudas al desarrollo rural bajo el Método LEADER es convertir a las zonas rurales en lugares más atractivos y adecuados para vivir y trabajar, en los que las condiciones de 
vida atraigan a personas de todas las edades, invirtiendo así el proceso de envejecimiento y despoblación de las mismas, dotándolos de todos los equipamientos y servicios que contribuyan en su desarrollo (MAPA, 2004).

Aparece como un modelo que "significó la puesta en marcha de un nuevo enfoque del desarrollo rural que incorporó los conceptos de endógeno, integrado, innovador, demostrativo y participativo" (Actualidad LEADER, 1998: 16). Un nuevo planteamiento que, para muchas de las zonas beneficiadas, ha supuesto el inicio de una dinámica positiva de desarrollo global e integral, con un claro incremento de la actividad económica y la paralización de la despoblación de las comarcas menos desarrolladas. Además, el Método LEADER trajo consigo la novedad de implicar a la población local como verdadero motor de gestión en el desarrollo de las actividades de la Iniciativa. Algunos territorios beneficiados por las ayudas al desarrollo rural, frente a la progresiva marginalización que experimentaron desde mediados del siglo veinte, registran un dinamismo creciente a partir de 1990, vinculado a la aplicación de políticas orientadas a paliar desequilibrios territoriales (Hernández y Rico, 2008).

Es importante destacar que el Método LEADER se acoge a la doble dimensión del desarrollo rural (Esparcia, 2012). Por un lado, la referente a la diversificación productiva, en la que se incluyen tanto actividades complementarias a los sectores más tradicionales como otras más innovadoras; por ello se habla, cuando se procesa el concepto de desarrollo rural, de actividades como el turismo rural o pymes en general y sobre otras destinadas a sectores estratégicos como el medio ambiente y la formación. Por otro lado, como segundo eje del desarrollo rural, la dinamización de la sociedad local, quizás una de las mayores preocupaciones por parte de los gestores de LEADER, de tal modo que se la involucre en la toma de decisiones estratégicas y se mejore el capital humano que actúa como actor y benefactor en todo este proceso.

Como se ha comentado anteriormente, se realizan inversiones en distintas actividades productivas, aunque este trabajo se centra en las ayudas al sector del turismo. Estas inversiones van a estar basadas en la cofinanciación, así todos los proyectos que se realicen tendrán participación de la UE mediante sus Fondos Estructurales (FEDER, FEOGA-O, FSE o en la actualidad, FEADER), de las administraciones nacionales (Central, Autonómica y Local) y cuando sean "medidas productivas", de agentes privados.

El primer objetivo de este trabajo es estudiar la evolución de las inversiones de turismo rural en las sucesivas etapas de LEADER y PRODER en Extremadura. En las primeras etapas y al igual que en otros territorios españoles y europeos, la implantación de LEADER I, LEADER II y PRODER I supuso la creación de una infraestructura de alojamientos y fue la medida donde se concentraron las inversiones más cuantiosas de estas ayudas. Casos como los 53 Grupos de LEADER I (Blanco y Benayas, 1994), los Grupos de Acción Local del NO de la región de Murcia (García, 2011), los localizados en las zonas de montaña de la Comunidad Valenciana (Hernández y Rico, 2008) y, más concretamente en la provincia de Alicante (Candela et al, 1995); los 14 Grupos LEADER I y II de Galicia (Pérez y López, 2005) o los LEADER II de Andalucía (Toledano y Gessa, 2002, Márquez et al, 2005) donde se realizaron numerosos proyectos destinados a la construcción y rehabilitación de casas rurales, de apartamentos turísticos, albergues juveniles, hostales y restaurantes generándose rentas complementarias a las generadas 
por la actividad agraria principal. O en otros territorios tan alejados de Extremadura pero que en sus características económicas y naturales no son tan divergentes como es el caso griego (Iakdviddu, 2002).

En la siguiente etapa de LEADER + y PRODER II se centraron en ayudar a los agentes del mundo rural a reflexionar sobre el potencial de su territorio en una perspectiva a más largo plazo, se pretendió diseñar una estrategia integrada de desarrollo, teniendo en cuenta la valorización de los productos y recursos locales, la introducción de nuevos conocimientos y tecnologías, apostando de forma muy directa por la calidad (Pillet, 2008). Se pretendía avanzar en una estrategia de turismo más elaborada y relacionada con las demás actividades de la comarca (Gómez et al, 2007). No sólo centrarse en la construcción de una oferta hotelera dispersa, sino en potenciar la identidad natural y cultural, información turística o creación de rutas temáticas como en la sierra norte madrileña (Morán y Sotelo, 2002). Por eso, en esta etapa han aparecido, dentro de las inversiones de LEADER, acciones como la puesta en marcha de museos y centros de interpretación, guías culturales, exposiciones, campañas de difusión, denominaciones de origen, marcas de calidad, etc (Andrés y Espejo, 2006). Siguen siendo además, las ayudas más numerosas en Grupos de las zonas rurales de montaña o más desfavorecidas de regiones como la extremeña (Nieto y Cárdenas, 2015), Castilla La Mancha (Mondéjar et al, 2008) o la montaña valenciana (Hernández, 1998; Pitarch y Arnandis, 2014).

En el último período ejecutado (2007-2013) esta medida tiene como objetivo contribuir a la revitalización económica a través del apoyo a la creación, modernización y/o ampliación de proyectos de inversión relacionados con el sector turístico. Se pretende seguir avanzando en una mejora de la calidad de la oferta turística con la puesta en marcha de actividades complementarias y de turismo alternativo de carácter innovador y diferenciado de la oferta existente, con especial atención en aquellas actuaciones de gestión conjunta de uno o varios servicios o al desarrollo de productos que integren una oferta combinada de diversos servicios turísticos. Básicamente, en este último periodo de programación, la medida destinada a turismo se puede considerar como No Productiva, puesto que a través de ella se pretende contribuir en la creación de un "producto turístico", fortaleciendo y complementando la infraestructura actual del sector, como se ha podido ver, con actividades como centros de información e interpretación, pequeños museos, señalización de los lugares turísticos, etc,

El segundo objetivo de este trabajo, el cual le asigna un carácter innovador, es la localización en el territorio extremeño de las actuaciones en turismo rural de LEADER en los últimos 25 años y su análisis a través de una serie de indicadores de contexto (volumen de inversiones y proyectos por población y superficie, crecimiento de la población, índice de envejecimiento y actividad económica). Así, se pretende comprobar si las inversiones en este sector se localizan en la región extremeña en zonas de montaña y más deprimidas económica y socialmente, como se ha estudiado en trabajos previos (Gil de Arriba, 1999; Zapatero y Sánchez, 1999; Delgado y De La Fuente, 2000; Gutiérrez, 2000; Ruiz, Frutos y Climent, 2000; Alario y Baraja, 2006; Vargas y Mondéjar, 2006; Pillet, 2008; Cejudo y Navarro, 2009; Nieto y Gurría, 2010; Nieto y Cárdenas, 2015) y si las ayudas en turismo en estos territorios menos dinámicos están logrando su objetivo primordial: el mantenimiento e incluso incremento de la población. 


\section{METODOLOGÍA Y FUENTES}

Para analizar las acciones en turismo rural del Método LEADER en Extremadura se han establecido las siguientes fases metodológicas: la primera, definir las medidas de turismo que se van analizar de LEADER y PRODER en los distintos periodos de programación europea; segunda, diseñar una base de datos cartográfica y alfanumérica con los datos de las inversiones en turismo en las distintas etapas y en los diferentes Grupos complementadas con indicadores demográficos y económicos relevantes y que representen la realidad territorial de los distintos espacios extremeños; en tercer lugar, un análisis evolutivo de la gestión de estas ayudas; y por último, un análisis estadístico, mediante el método NADIR, con el fin de estudiar la eficacia y la eficiencia de las ayudas.

De este modo, en la primera parte de este trabajo se estudió la normativa de los distintos períodos de programación (desde LEADER I han sucedido cuatro: 1991-1994; 19951999; 2000-2006 y 2007-2013) y cómo las acciones de turismo han venido definidas de forma diferente en sus reglamentos. Por ello, se optó por homogeneizarlas, para su mayor entendimiento, en la siguiente tabla:

Tabla 1

HOMOGENEIZACIÓN DE MEDIDAS LEADER, PRODER y FEADER

\begin{tabular}{|l|l|}
\hline Período de Programación & Acción 3. Turismo \\
\hline LEADER I (1991-1994) & Turismo rural \\
\hline LEADER II (1995-1999) & B3. Turismo rural \\
\hline LEADER + (2000-2006) & 108. Turismo rural \\
\hline PRODER I(1995-1999) & 3. Agroturismo y 4. Turismo Local \\
\hline PRODER II (2000-2006) & 3. Turismo rural \\
\hline FEADER 2007-2013 & 313. Fomento de actividades turísticas \\
\hline
\end{tabular}

Fuente: elaboración propia.

En la segunda fase de este trabajo ha sido necesaria la construcción de, por un lado, una base de datos cartográfica, y por otro, alfanumérica, con las inversiones de LEADER en turismo rural y las variables que se han estimado como definitorias para analizar el impacto de estas inversiones: población, superficie y actividad económica.

Los datos cartográficos han sido elaborados a partir de la cartografía municipal de la BTN 1:100.000 del Instituto Geográfico Nacional, más concretamente se han utilizado las capas vectoriales de los municipios y los núcleos de población y además, a partir de ellas se ha calculado la superficie municipal en $\mathrm{Km}^{2}$.

Los datos alfanuméricos se han adquirido de diversas fuentes y se han codificado a nivel municipal para introducirlos en la capa poligonal de municipios de Extremadura (obtenida de la BTN100) y a nivel comarcal, agrupados por Grupo de Acción Local (GAL) a través de los datos facilitados por la Red Extremeña de Desarrollo Rural. 
La obtención de los primeros datos, los demográficos, se ha hecho a través del INE (Instituto Nacional de Estadística) y posteriormente se han elaborado datos medios de variables de natalidad, mortalidad, crecimiento vegetativo, crecimiento de la población, saldos migratorios e índices de juventud y de vejez de los distintos períodos y, a nivel global, de los 20 años desde LEADER II-PRODER I (1995-2015) durante los cuales ya actuaban estas ayudas en más del $80 \%$ del territorio extremeño.

Las variables socioeconómicas se han extraído del Atlas Socioeconómico de Extremadura 2014. El Atlas comprende una selección de datos estadísticos de la región extremeña a nivel municipal, la cual aporta metodologías y estimaciones propias de indicadores como los escogidos en este estudio, por ello que se haga necesaria su descripción. El Índice de Actividad económica es un índice comparativo de la actividad económica municipal y se obtiene en función del impuesto correspondiente al total de actividades económicas empresariales (industriales, comerciales y de servicios) y profesionales, así, el valor del índice expresa la participación de la actividad económica (en tanto por diez mil) de cada municipio respecto al total de Extremadura; en segundo lugar, el Índice de Actividad comercial, también un índice comparativo de la importancia del comercio de cada municipio en función del impuesto de actividades económicas (IAE) correspondiente a las actividades del comercio mayorista y minorista, cuyo valor refleja el peso relativo (tanto por diez mil) de la actividad comercial municipal respecto al total de la región, y de igual manera, los índices de Actividad industrial y de Restauración y bares; el Índice de Productividad se calcula en función de la ratio del PIB total y la población ocupada, de tal manera que se trata de un índice simple que se obtiene con base: PIB/ ocupado de Extremadura $=100$.

Por último, los datos relativos al Método LEADER, información que se ha generado a partir de la facilitada por la Consejería de Medio Ambiente y Rural, Políticas Agrarias y Territorio del Gobierno de Extremadura en formato .xls, con un diseño establecido. Se obtuvieron 24 documentos, uno por GAL y de cada período de programación, donde aparecían todos los proyectos comprometidos con el número de expediente de cada uno, el benefactor, el municipio y la inversión total y por fondos de financiación (más de 11.000, durante los 25 años en los que se lleva aplicando Leader en Extremadura). Toda esta información fue trasladada a nuevos archivos .xls para trabajarlos a continuación como Base de Datos, calculando posteriormente sumatorios y realizando diversas consultas, obteniendo finalmente la inversión total en turismo de cada período, por fondo de financiación y el número de proyectos, tanto a nivel municipal como a nivel de GAL. Los últimos datos disponibles están fechados a 31 de diciembre de 2015.

Con todos estos datos procesados se realizó, en la tercera fase, un análisis evolutivo de las inversiones en turismo para examinar, por un lado, las tendencias en los distintos períodos, es decir, si se han ido reduciendo, como ha sucedido a nivel nacional (Pitarch y Arnandis, 2014), si la participación privada es superior a las demás medidas productivas, como la destinada a PYMES o a la Valorización del Potencial Agrario, si se ha localizado en territorios donde existía una oferta turística o en espacios con gran riqueza natural y paisajística pero todavía sin explotar, y por otro, la tipología de proyectos: alojamientos turísticos, restaurantes, campaña de promoción, asistencia a ferias, difusión en webs, etc. 
En la última fase, se ha incluido un análisis de la relación existente entre el presupuesto, la situación demográfica, la localización territorial y la actividad económica de los distintos Grupos. Con esto, se pretende comprobar, en el sector turístico, el grado en que se consiguen los logros buscados a través de las inversiones y del número de proyectos y poder medir el impacto territorial al relacionarlos con la superficie comarcal y poblacional. Es decir, comprobar el grado de eficacia, la capacidad de movilizar el mayor número de proyectos, y el grado de eficiencia, la inversión relacionada con su población y territorio, es decir, la productividad de estas inversiones (Márquez et al, 2006). Para ello, se ha empleado la metodología desarrollada por Márquez et al (2006) a través del método estadístico NADIR, se ha realizado una homogeneización de las variables con los indicadores de proyectos (nivel de eficacia) e inversiones (nivel de eficiencia) por municipios y población, para después establecer una categorización de los resultados de cada GAL a través del método del Punto Ideal.

Se calcula el valor obtenido por cada GAL, tanto de los proyectos (eficacia) como de las inversiones (eficiencia) mediante la siguiente ecuación (Método NADIR):

\section{V eficacia $=N-$ Valor mínimo / Valor máximo - Valor mínimo$$
\text { V eficiencia }=\text { Valor máximo }-N \text { / Valor máximo }- \text { Valor mínimo }
$$

Una vez obtenidos los resultados para cada Grupo, nos permite ordenar los diferentes comportamientos mediante el método del Punto Ideal con P2, un modelo que minimiza las diferencias que existen entre el nivel deseado y percibido para cada uno de los atributos que conforman las dimensiones de calidad del servicio. Se construyen los valores ideales de cada escenario y a P2 se le denomina de valoración ideal. Con ello se identifica cada P2 de las comarcas por la distancia entre el vector ideal y el siguiente vector. Cuanto menor sea la distancia entre ambos vectores, mayor será la posibilidad de alcanzar el óptimo de sostenibilidad. La ecuación que se aplica es:

$$
P 2=\sqrt{(1-v 1})^{2}+(1-\mathrm{v} 2)^{2}+(1-\mathrm{v} 3)^{2}+(1-\mathrm{v} 4)^{2}
$$

donde:

- $v 1=$ es el valor de eficacia ( $\mathrm{n}^{\circ}$ de proyectos) de cada comarca en superficie.

- v2 = es el valor de eficacia $\left(\mathrm{n}^{\circ}\right.$ de proyectos) de cada comarca en población.

- v3= es el valor de eficiencia (inversiones) de cada comarca en superficie.

- v4= es el valor de eficiencia (inversiones) de cada comarca en población.

Se obtendrá una tipología de comarcas en función de la eficacia y eficiencia de las ayudas al turismo rural y se localizarán en el espacio extremeño, con la cartografía de los Grupos de Acción Local elaborada a través de la información vectorial de la BTN100 y la información alfanumérica de la Red Extremeña de Desarrollo Rural. 


\section{ACCIONES DE TURISMO RURAL EN EXTREMADURA}

En Extremadura, LEADER comienza en 1991 con LEADER I en sólo cuatro comarcas: Sierra de Gata, Valle del Jerte, Alcántara y La Serena. Es a partir de 1995 cuando este modelo se consolida al formarse 22 Grupos de Acción Local (10 Grupos LEADER II y 12 Grupos PRODER) que agrupaban un total de 311 municipios de los 380 existentes en la región. En la siguiente etapa (2000-2006) se amplió a 24 Grupos, que son los que se han mantenido hasta el momento actual, y los cuales aglutinan a todos los núcleos extremeños excepto los cuatro considerados urbanos, con más de 40.000 habitantes: Badajoz, Cáceres, Mérida y Plasencia (Figura 1).

\section{Figura 1}

\section{LOCALIZACIÓN DE LOS GRUPOS DE DESARROLLO RURAL EN EXTREMADURA}

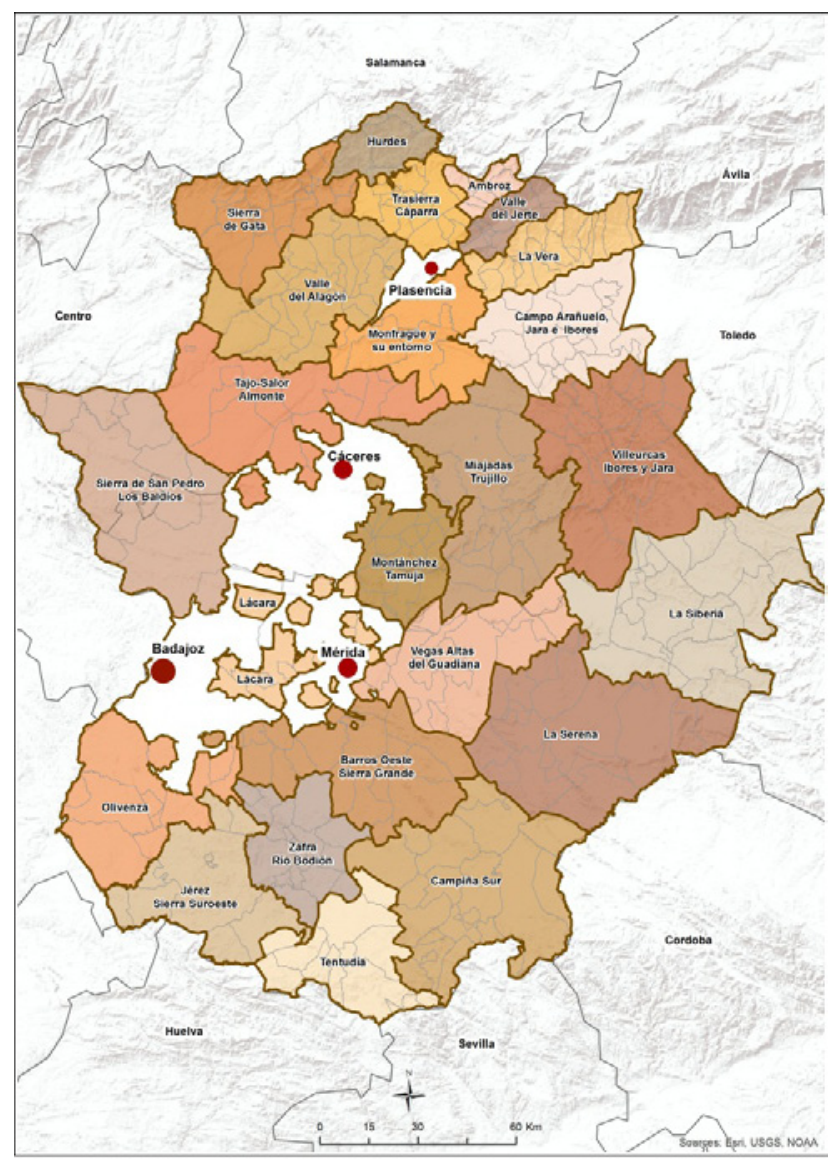

Fuente: Nieto y Cárdenas (2015). 
Con la aparición de LEADER, como se ha comentado en epígrafes anteriores, una de las orientaciones de estas inversiones fue el turismo rural, que se alineará en torno a tres ejes prioritarios (Pitarch y Arnandis, 2014):

a) La creación de una oferta turística que aporte ingresos a la renta familiar, que dé salida a los productos agrícolas y ganaderos y que comercialice la artesanía.

b) La conservación y rehabilitación del patrimonio sociocultural e histórico artístico.

c) La revitalización de la vida local.

Estos programas no han sido en modo alguno un programa de desarrollo turístico, pero han funcionado como impulsores de este sector al presentar, en todos sus períodos de programación, acciones específicas destinadas al mismo, siendo además de las de mayor volumen de financiación. A nivel nacional, las inversiones en turismo rural de LEADER I supusieron el 50,2\% de la financiación total del programa, donde más del $40 \%$ fueron destinadas a rehabilitar o crear nuevos alojamientos turísticos (MAPA, 2004). Posteriormente, en las siguientes etapas se ha contemplado también esta línea como una de las prioritarias, aunque hayan ido disminuyendo sus aportaciones: por ejemplo, en LEADER II- PRODER I a un 32,4 y un 23\% respectivamente y la última etapa con datos finalizados, LEADER +, con el $25 \%$ del total de inversiones (Cánoves et al, 2006). Estas menores aportaciones se han debido al ir enfocándose las estrategias de desarrollo de las comarcas, no sólo a la creación de alojamientos rurales como en las primeras etapas sino a actividades complementarias relacionadas, por una parte, con el incremento de inversiones en revalorización del patrimonio y, por otra, con la dotación de servicios en los núcleos rurales que son financiadas en otras medidas: las destinadas a conservación del medio rural y la segunda a PYMES. Artesanía y Servicios.

\subsection{Evolución de las Inversiones}

En la primera etapa de LEADER I, el turismo fue la actividad que mayor volumen de inversiones recibió con casi un 37\% del total del período, aunque no se llegó a los umbrales de este sector en el total de España, donde se invirtió más del 50,2 \% en acciones de turismo rural (MAPA, 2004). El apoyo al sector turístico se estructuró en dos bloques:

- Acciones dirigidas a proyectos productivos (alojamientos, restaurantes, puntos de ventas, etc...). En Grupos como Sierra de Gata se aprobaron diez proyectos de casas rurales, una casa de reposo, un albergue refugio, 1 granja escuela, dos puntos de degustación de productos locales, un restaurante, dos museos (uno etnográfico y el otro dedicado al aceite y al vino) y un picadero de caballos. Con esto, se puede comprobar la diversidad en la oferta financiada.

- Acciones no productivas (oficinas de promoción turística, proyectos de adecuación de zonas, proyectos de señalización y campañas de promoción). Ponemos el ejemplo del grupo de La Serena, que en este apartado financió la asistencia a ferias del turismo como FEVAL, videos de promoción turística como el titulado "La Serena: el canto de la estepa", material de promoción como folletos, cds y anuncios en prensa, y señalización de rutas naturales en las zonas de los embalses. 
LEADER I supuso una toma de contacto con este tipo de políticas europeas y un efecto multiplicador en las demás zonas rurales extremeñas, que al observar el buen funcionamiento de esta Iniciativa, se agruparon en Grupos de Acción Local no preexistentes, elaboraron una estrategia de desarrollo y concursaron para participar en la siguiente fase donde se pasó a 22 Grupos (diez de ellos a LEADER II y doce a PRODER I).

En la segunda etapa y con la consolidación territorial de estas ayudas en Extremadura con la aprobación de veintidós Grupos LEADER II y PRODER I ${ }^{1}$, se destinan diferentes medidas al turismo. En LEADER II, dentro del Programa de Innovación Rural (Medida B), se le denomina B3- Turismo rural y se introduce como novedad el término Innovación por la importancia que se otorga desde la Comisión a que todos los proyectos que se beneficien de ayudas de LEADER II tengan un carácter innovador y de demostración en sus propuestas. La financiación por parte de la UE de la medida B3 viene de parte del FEOGA-O y del FEDER. En PRODER I se presentan dos medidas dedicadas al Turismo, Medida 3 (Agroturismo) y Medida 4 (turismo local), que se agrupan en una sola para poder compararla con LEADER (Tabla 1). La primera viene financiada por el FEOGA-O y la segunda por el FEDER.

En el sector turístico, los objetivos de LEADER II se centraron en la creación de polos de atracción turística y de centros de información y en lograr vincular la oferta turística con la demanda, mediante inversiones individuales o colectivas novedosas (incluidas las relacionadas con las actividades agrícolas), en pequeñas infraestructuras públicas vinculadas a las necesidades derivadas de la oferta turística, en inventario, restauración y revalorización de edificios de carácter histórico y parajes rurales de interés turístico, en actividades de promoción, estudios de mercado y creación de sistemas de reserva y la puesta en marcha de nuevos productos de turismo rural (incluido el turismo cultural y natural). Los objetivos de PRODER I en turismo también se centraron en actividades de promoción, en fomentar nuevas actividades de turismo natural, patrimonial, gastronómico, etc., pero sobre todo en estimular la creación de plazas turísticas en el medio rural, una infraestructura de alojamientos y restaurantes, y en todas estas actividades no se impulsó el carácter innovador de las propuestas al no obligarlo su normativa.

En LEADER II-PRODER I, se destinaron a esta medida 32.670.624 Euros (Tabla 2), lo que supone un $25,4 \%$ del total del Programa (la media española se destinó un $27,5 \%)$. Así, se puede destacar, como primera aportación, que en este período las acciones dedicadas en exclusividad al turismo rural pierden importancia con respecto a la etapa anterior (habían supuesto un 37\% en Extremadura, y en España un 50\%) y son levemente inferiores a la media española. Por agentes, los Fondos Estructurales participaron con un 32,9\% (FEDER, 15,1\% y FEOGA-O, 17,8\%); el Ministerio de Agricultura con un 2,3\%, la Junta de Extremadura 5,8\%, Administración Local con 5,0; y por último la participación privada con un 53,65\%. Aunque sí hay que destacar que en PRODER I las aportaciones al turismo sí fueron porcentualmente más significativas en la totalidad de gestión del programa (PRODER I, 28,13\%; LEADER II, 23,34\%) y superiores también a la media española $(23,2 \%)^{2}$.

\footnotetext{
1 Decisión de aprobación de la Comisión C (95) 1309/7 de 27.VII.1995.

2 Inversión estatal para turismo rural. 183,4 mill. Euros (23,3 \%). Inversión Privada, 50 \%. Fuente: MAPA
} (2004) 


\section{Tabla 2 \\ INVERSIONES EN TURISMO EN LOS DISTINTOS PERÍODOS DEL MÉTODO LEADER}

\begin{tabular}{|c|c|c|c|c|}
\hline Períodos & $\begin{array}{c}\text { Inversiones en } \\
\text { Turismo }(\% \\
\text { respecto al total) }\end{array}$ & $\begin{array}{c}\text { Proyectos en } \\
\text { Turismo } \\
(\% \text { respecto al } \\
\text { total) }\end{array}$ & $\begin{array}{c}\text { Inversiones } \\
\text { Totales }\end{array}$ & Proyectos \\
\hline LEADER II- PRODER I & $32.670 .624(25,4 \%)$ & $651(19,3 \%)$ & 128.608 .329 & 3.372 \\
\hline LEADER + PRODER II & $43.209 .173(22,5 \%)$ & $732(20,1 \%)$ & 195.027 .487 & 3.638 \\
\hline FEADER & $42.139 .632(20,1 \%)$ & $673(16,7 \%)$ & 209.612 .646 & 4.022 \\
\hline TOTAL & $118.019 .429(22,7 \%)$ & $2056(18,7 \%)$ & 533.248 .462 & 11.032 \\
\hline
\end{tabular}

Fuente: elaboración propia.

En la siguiente etapa (2000-2006), con LEADER +, vuelve a cambiar el reglamento ${ }^{3}$, y las actuaciones de turismo rural se enmarcan fundamentalmente en el Capítulo 1: Plan de Desarrollo Rural, cuya finalidad es articular el desarrollo de la zona en torno a un aspecto predominante que resulte característico de la identidad del territorio en donde se agrupen todos los sectores económicos. Dentro de este capítulo interesa la Medida 108, dedicada en exclusiva al turismo. En PRODER II se presentan, también, proyectos de desarrollo integrados de las comarcas rurales ${ }^{4}$, pero no se estima oportuno en su reglamento la obligatoriedad de dividir este programa por sectores como en LEADER + y plantear unas previsiones financieras iniciales en los mismos, sino que cada GAL iría destinando en el transcurso del programa las ayudas a los distintos sectores dependiendo de las necesidades de los territorios en cada momento, aunque sí se estipula la obligatoriedad de realizar proyectos que participen en el fomento del turismo en el medio rural. En esta etapa las aportaciones de la UE se canalizarán exclusivamente a través del FEOGA-O en ambos programas.

En este período se destinaron más de 43 millones al turismo, aunque hay que diferenciar entre LEADER + (más de 17 millones de euros, 14,4\% del total de inversiones) y PRODER II, con más de 26 millones suponiendo el 26\% (Tabla 2). Se reducen porcentualmente las aportaciones al turismo con respecto al período anterior, más acusada en LEADER (de LEADER II a LEADER + pasan de un 23,3 a un 14,4\%) que en PRODER (disminuyen sólo de un $28,1 \%$ a un 26,0\%). Se debe a dos razones, primero, en LEADER + se exigió, por parte de normativa de la Comisión Europea, que las inversiones en esta nueva etapa estuvieran relacionadas con un factor aglutinador de desarrollo de la comarca y, algunas de ellas, como Miajadas-Trujillo, La Serena y Campo Arañuelo, optaron por la valorización de productos locales o la agroindustria de un determinado sector (porcino,

3 Reglamento (CE) No 1260 del Consejo, de 21 de junio de 1999, por el que se establecen disposiciones generales sobre los Fondos Estructurales.

4 Reglamento (CE) N $1260 / 99$ y Decisión de la Comisión de las Comunidades Europeas $\mathrm{N}^{\circ} \mathrm{C}$ (2000) ES 16.1.P.O.010, de 29 de diciembre por el que se aprueba El Programa Operativo Integrado para la Comunidad Autónoma de Extremadura. 
olivo, etc). Por ello, destinaron menores recursos para el turismo. Además, desde las evaluaciones de la Comisión Europea de LEADER I y LEADER II, se mostraba como un error el enorme peso que tenían las inversiones en turismo rural en los mismos. En PRODER, por estar funcionando dentro del Programa Operativo Integrado de Extremadura, su funcionamiento no fue tan estricto en cuanto a las inversiones y por ello muchos de los Grupos decidieron seguir priorizando el turismo rural como medida de inversión, ya que en la primera etapa les proporcionó óptimos resultados. La segunda razón coincide con la naturaleza económica de los Grupos, pues la mayoría de los PRODER se encuentran localizados en zonas con gran riqueza paisajística (montañas, riberos, embalses,..) o patrimonial y un tejido empresarial menos desarrollado, y por ello pusieron en marcha un mayor número de proyectos dedicados a la implantación de nuevos alojamientos o instalaciones relacionadas con el turismo y no a la mejora o implantación de nuevas empresas agrarias o de servicios.

En el último período finalizado, con las ayudas entre 2007 y 2013, las inversiones de los Grupos de Acción Local han venido determinadas por el Reglamento del FEADER $^{5}$ en el Plan Nacional de Desarrollo Rural y en el Programa de Desarrollo Rural de Extremadura 2007-2013. En este período, ya no existen diferencias entre LEADER y PRODER, sino que todos los Grupos de Acción Local gestionan las ayudas bajo el Eje 4. Método LEADER, aunque siguen presentando el mismo funcionamiento y sistema de trabajo. Dentro de las medidas subvencionables, las dedicadas al turismo se enmarcan en el Eje 3. Mejora de la calidad de vida y de la economía en las zonas rurales, y más concretamente, en la Submedida 313. Fomento de las actividades turísticas, incidiendo su normativa en la importancia del turismo como un sector en desarrollo fundamental en muchas de sus zonas rurales, creándose a través de él nuevas posibilidades de empleo y aumentándose por lo tanto la atracción a ellas. Así, esta medida tiene como objetivo contribuir a la revitalización económica de los territorios rurales a través del apoyo a la creación, modernización y/o ampliación de proyectos de inversión relacionados con el sector turístico.

A través de esta Submedida se persigue la mejora de la calidad de la oferta del sector turístico en el medio rural; la puesta en marcha de actividades complementarias y de turismo alternativo de carácter innovador y diferenciado de la oferta existente, con especial atención en aquellas actuaciones de gestión conjunta de uno o varios servicios turísticos o al desarrollo de productos que integren una oferta combinada en el medio rural (alojamiento, restauración, actividades de ocio, comercialización de productos locales y/o artesanales, etc.); la puesta en marcha de infraestructuras turísticas dirigidas a la información, atención, acogida y recepción del visitante (puntos de información y señalización turística, mejora del acceso a lugares de interés turísticos, centros de reserva turística, etc.); actuaciones que mejoren la comercialización y promoción de los productos y servicios turísticos, especialmente aquellas que aprovechen las ventajas de las nuevas tecnologías de la información y la comunicación; señalización de entornos y rutas de interés; actividades de divulgación genéricas; y creación, ampliación y mejora de los establecimientos turísticos de capacidad reducida (hasta un máximo de 50 pla-

$5 \quad$ Reglamento (CE) no 1698/2005; 
zas). Se pretende consolidar un producto turístico, una estrategia de diseño de comarca turística, con la creación y mejora de infraestructuras recreativas y servicios turísticos y con proyectos de carácter innovador y diversificador, que creen o consoliden empleo, prestando especial preocupación en los colectivos de mujeres, jóvenes y discapacitados, y que supongan mejoras ambientales, e ir disminuyendo las inversiones que sólo vayan destinadas a la creación dispersa de alojamientos rurales tradicionales (casas rurales, albergues, hostales, campings, restaurantes, etc).

Se han ejecutado 673 proyectos $(16,7 \%$ respecto al total) con una inversión total de más de 42 millones de euros $(20,1 \%)$. Comparando con etapas anteriores, han disminuido tanto el número de proyectos como las inversiones finales (Tabla 2) a favor del aumento de las inversiones en las demás medidas productivas de LEADER: Pymes y servicios $(36,6 \%)$, rehabilitación del patrimonio natural y cultural $(18,9 \%)$ y revalorización de la producción agraria (12,4\%). Por Fondos, las ayudas del FEADER han supuesto el 42,1\%, las otras dos Administraciones un 10,2 \% (AGE y Junta de Extremadura, ambas con un 5\%, porque ya no hay participación financiera de la Administración Local) y las privadas el $47,02 \%$. Aunque se ha reducido la aportación global en este período, las cifras de la participación privada difieren mínimamente con el período anterior $(48,2 \%)$ por lo que la población local se sigue implicando en invertir en su territorio y en actividades turísticas.

\subsection{Evolución de la tipología de los beneficiarios}

En LEADER II, se ejecutaron 347 proyectos (el 16\% del total), un porcentaje poco superior al número de beneficiarios (el 6\%), por lo que cada subvención se concedió a un promotor diferente, evitando así la concentración de proyectos en uno mismo o en pocas asociaciones, como ha ocurrido con otras submedidas. Por tipología de beneficiarios, se observa también la diversidad de los mismos (tabla 3), destacando que los más numerosos han sido empresarios individuales (personas físicas), con 113, y administraciones y colectivos con 77. Con PRODER I se realizaron 304 proyectos, el $24 \%$ del total del programa, y supone una media de 9.000 Euros por proyecto, cantidad mayor que en LEADER II ya que en este último se crearon 347 proyectos, con 757.319 euros menos de efectivo. En PRODER I el número de beneficiarios es inferior a los proyectos totales (304 proyectos y 254 beneficiarios) debido a que algunos de los segundos, por su mayor cuantía económica, se dividieron en dos o tres subproyectos o certificaciones, pero iban destinados al mismo. Por ejemplo, para la creación de una nueva casa rural se ejecutaban diferentes proyectos ( $1^{\circ}$ proyecto: diseño del alojamiento; $2^{\circ}$ proyecto: construcción; $3^{\circ}$ proyecto: mobiliario y difusión del alojamiento). Por tipología, las más numerosas son, como en LEADER II, los empresarios individuales con 107, seguidos de las Administraciones con 69 (en LEADER II la segunda más numerosa eran las asociaciones) (tabla 3).

En LEADER+ - PRODER II, la tipología de beneficiarios más numerosa es la de asociaciones, las cuales pueden ser de turismo rural de las comarcas o los Grupos de Acción Local que invirtieron en campañas de promoción de la misma y en asistencia a Jornadas o Ferias (Tabla 3). En PRODER II le siguen las personas individuales (hombres 
y mujeres con más del $30 \%$ entre ambas) con proyectos dedicados a la creación de alojamientos o restaurantes, mientras que en LEADER + son las sociedades civiles con un $25 \%$, debido a que se destinaron mayores recursos a proyectos turísticos no productivos.

Se puede concluir con que en ambas etapas ${ }^{6}$ la participación de nuevos empresarios bajo la condición de autónomos o personas físicas ha sido la más numerosa. Con las ayudas al desarrollo rural dedicadas al turismo se ha logrado incentivar y motivar a personas que no tenían previamente un negocio turístico, embarcándose así en nuevos proyectos.

Destacar, además, la creación de nuevas asociaciones. Se ha conseguido, en cada comarca, agrupar a la mayoría de los empresarios turísticos en asociaciones de turismo rural con el fin de colaborar en actividades como la difusión en webs, fiestas, ferias de turismo..., como oferta conjunta de un territorio. Claros ejemplos son los de la Asociación de Turismo rural Valle del Jerte, ATUMON, en Monfragüe y su Entorno, ATUVA, en el Valle del Ambroz, la Asociación de Turismo rural Tierras de Granadilla, Asociación de Turismo Sierra de San Pedro o TURISGATA- en Sierra de Gata.

Tabla 3

BENEFICIARIOS FINALES EN LAS AYUDAS AL TURISMO RURAL

\begin{tabular}{|l|r|r|r|r|r|r|}
\hline $\begin{array}{l}\text { Beneficiarios } \\
\text { Finales }\end{array}$ & $\begin{array}{l}\text { LEADER } \\
\text { II }\end{array}$ & $\begin{array}{c}\text { PRODER } \\
\text { I }\end{array}$ & $\mathbf{1 9 9 5 - 1 9 9 9}$ & $\begin{array}{c}\text { LEADER } \\
+\end{array}$ & $\begin{array}{c}\text { PRODER } \\
\text { I }\end{array}$ & $\mathbf{2 0 0 0 - 2 0 0 6}$ \\
\hline Personas Físicas & 113 & 107 & 220 & 67 & 111 & 178 \\
\hline Empresas & 55 & 28 & 83 & 57 & 33 & 90 \\
\hline Administraciones & 77 & 69 & 146 & 28 & 34 & 62 \\
\hline Asociaciones & 81 & 48 & 129 & 66 & 158 & 224 \\
\hline Cooperativas & 2 & 2 & 4 & 9 & 0 & 9 \\
\hline Total & 328 & 254 & 582 & 227 & 336 & 563 \\
\hline
\end{tabular}

Fuente: elaboración propia.

\subsection{Evolución de la tipología de proyectos y creación de nuevas plazas hoteleras}

En LEADER II-PRODER I, las actividades predominantes fueron las campañas de promoción (193 proyectos), la apertura de casas rurales (115 proyectos), mejora de instalaciones turísticas ya existentes (60) y mejora del entorno y patrimonio histórico (56). Con mucha menor presencia está la apertura de campings y albergues (15), museos (5) o restaurantes (31). En LEADER II destaca la creación de nuevos establecimientos con la figura de casas rurales y en PRODER I la diversificación de la oferta entre casas rurales, hoteles y albergues (Tabla 4). Se crearon por lo tanto, en esta etapa, 1.415 nuevas plazas hoteleras, destacando Grupos como Valle del Jerte (350), Campiña Sur (251) y Campo Arañuelo (250), mientras que en PRODER I 2.181 nuevas plazas, destacando

6 Los datos de beneficiarios finales del período 2007-2013 todavía no nos han sido facilitados aunque si las inversiones por estar realizando la Consejería de Agricultura el cierre del mismo. Se nos han facilitado el nombre del beneficiario pero no si tiene la condición de autónomo (persona física), empresa, gerente de asociación o cooperativa. 
Villuercas-Ibores, con 446, seguida de La Vera y Zafra-Río Bodión con 383 y 279, respectivamente. Todos estos Grupos están localizados en zonas de montaña con una gran riqueza natural y paisajística, exceptuando el caso de Zafra-Río Bodión, enfocado a una riqueza patrimonial y cultural.

Tabla 4

TIPOLOGÍA DE PROYECTOS LEADER y PRODER

\begin{tabular}{|c|c|c|c|c|c|c|}
\hline $\begin{array}{l}\text { Tipo de } \\
\text { Proyecto }\end{array}$ & $\begin{array}{l}\text { Proyectos } \\
\text { LEADER II } \\
\text { PRODER I }\end{array}$ & $\begin{array}{l}\text { Inversiones } \\
\text { LEADER II } \\
\text { PRODER I }\end{array}$ & $\begin{array}{c}\text { Proyectos } \\
\text { LEADER + } \\
\text { PRODER II }\end{array}$ & $\begin{array}{l}\text { Inversiones } \\
\text { LEADER + } \\
\text { PRODER II }\end{array}$ & $\begin{array}{l}\text { Proyectos } \\
\text { FEADER }\end{array}$ & $\begin{array}{c}\text { Inversiones } \\
\text { FEADER }\end{array}$ \\
\hline $\begin{array}{l}\text { Albergues y } \\
\text { Campings }\end{array}$ & 15 & $1.132 .024,19$ & 6 & $1.005 .511,26$ & 12 & $836.776,26$ \\
\hline $\begin{array}{l}\text { Apartamentos } \\
\text { rurales }\end{array}$ & 0 & 0 & 21 & $3.496 .440,04$ & 41 & $6.369 .050,94$ \\
\hline $\begin{array}{l}\text { Apoyo Técnico } \\
\text { al Desarrollo } \\
\text { Rural/Asistencia } \\
\text { a Ferias }\end{array}$ & 74 & 2.495 .397 & 193 & $1.944 .624,07$ & 43 & $303.585,96$ \\
\hline Casa rural & 115 & $9.686 .850,67$ & 86 & $12.362 .537,36$ & 36 & $7.425 .470,21$ \\
\hline Hotel & 31 & $2.755 .757,22$ & 13 & $3.924 .834,87$ & 4 & $588.830,83$ \\
\hline $\begin{array}{l}\text { Instalaciones } \\
\text { turísticas }\end{array}$ & 63 & $3.947 .407,2$ & 34 & $4.812 .198,66$ & 88 & $6.594 .768,98$ \\
\hline $\begin{array}{l}\text { Mejora del } \\
\text { Patrimonio } \\
\text { Natural e } \\
\text { Histórico } \\
\end{array}$ & 56 & $3.247 .085,58$ & 52 & $968.510,2$ & 2 & $80.145,99$ \\
\hline $\begin{array}{l}\text { Modernización } \\
\text { y mejoras de las } \\
\text { instalaciones }\end{array}$ & 64 & $3.661 .795,97$ & 90 & $7.795 .634,84$ & 167 & $11.186 .167,7$ \\
\hline Museos & 5 & $119.421,18$ & 4 & $413.905,09$ & 4 & $312.160,32$ \\
\hline $\begin{array}{l}\text { Oficina de } \\
\text { Turismo }\end{array}$ & 4 & $49.315,64$ & 4 & $92.947,08$ & 5 & $60.737,61$ \\
\hline $\begin{array}{l}\text { Promoción } \\
\text { turística }\end{array}$ & 193 & $3.463 .188,13$ & 201 & $4.324 .066,4$ & 214 & $3.826 .403,53$ \\
\hline Restaurante & 31 & $2.112 .381,41$ & 28 & $3.885 .893,66$ & 24 & $3.770 .601,83$ \\
\hline Total & 651 & $32.670 .624,19$ & 732 & $45.027 .103,53$ & 640 & $41.354 .700,16$ \\
\hline
\end{tabular}

Fuente: elaboración propia.

En la siguiente etapa, LEADER+-PRODER II, aumentan los proyectos destinados a la difusión de las comarcas, a la asistencia técnica para los promotores (entre ambas con 394) y a la mejora y modernización de instalaciones con incorporación de nuevas actividades (90). Se empieza a detectar una disminución en la creación de oferta hotelera (28 restaurantes, 86 casas, 13 hoteles y aparece una nueva tipología los apartamentos rurales con 21), pues empezó a experimentarse una colmatación en la oferta de alojamientos, planteándose ampliar otras actividades complementarias que mantuvieran al turista un 
mayor número de días, tal y como indican las inversiones en otro tipo de proyectos. En cuanto a la oferta de nuevas plazas hoteleras, reseñar la creación de 3.059, superior en LEADER + (1.821) que en PRODER II (1.238), destacando Grupos de LEADER + como Tajo-Salor-Almonte con 616, Valle del Jerte con 352 y Sierra de Gata con 324 y en el caso de PRODER II, Villuercas-Ibores (324), Tentudía (175), Sierra de San Pedro (145) y La Vera (125). También mencionar que cuatro Grupos no crearon en este período ningún alojamiento rural nuevo, como son los casos de Campo Arañuelo y La Serena en LEADER + y Vegas Altas del Guadiana y Montánchez-Tamuja en PRODER II. Se encuentra una disparidad de territorios, los localizados en zonas de montaña dedicados sobre todo a ofertas de nuevos alojamientos y otros Grupos situados en zonas de regadío o penillanura en los que el turismo lo están enfocando a la comercialización de estos productos agrarios y a la mejora de un patrimonio histórico y cultural.

En la última etapa, con el FEADER, se han creado y modernizado 166 alojamientos, generando un total de 1.269 nuevas plazas, lo que supone una reducción con respecto a etapas anteriores. Se están diversificando las inversiones a través de otro tipo de actividades o proyectos imprescindibles para el desarrollo del sector, como son la señalización turística, adecuación de senderos, los centros BTT (bicicleta de montaña), museos y centros de interpretación y un amplio abanico de actividades promocionales que incluye la edición de materiales y el desarrollo de eventos turísticos (tabla 3). En total, se han creado o modernizado 286 empresas, siendo éstas las verdaderas impulsoras de creación de empleo, creando y consolidando 831 puestos de trabajo. Las mayores inversiones se siguen localizando en las zonas de montaña, con Grupos como Hurdes, La Vera, Tentudía, Valle del Alagón, Valle del Ambroz y Sierra de Gata.

\section{LA DIVERSIDAD TERRITORIAL DE LAS INVERSIONES EN TURISMO}

El territorio y la estructura de la población, en muchos Grupos muy envejecida, están condicionando el volumen total de inversiones o proyectos $\mathrm{y}$, por ello, se ha analizado una serie de indicadores de contexto, tales como las variables territoriales de cada Grupo, con los que exponer problemas demográficos y económicos como el envejecimiento y la concentración de la población y el índice de actividad económica, en ciertas zonas, relacionados con otros referentes a las acciones de desarrollo rural (número de proyectos, inversiones, empleo y participación privada). Se pretende localizar a los Grupos que han conseguido movilizar menos recursos, pero teniendo en cuenta que estamos analizando territorios con municipios con poca extensión y población (la dicotomía de municipios con mayor extensión territorial y núcleos más poblados en las zonas de penillanura y regadío de la provincia de Badajoz en contraste con municipios poco extensos y poblados de las zonas de montaña de la provincia de Cáceres). Se ha financiado, en estas zonas, un volumen de proyectos considerable, pero de menor cuantía económica, al estar ligados a la actividad turística, que las inversiones en otras medidas como Pymes y revalorización de la producción agraria, con proyectos de mayor cuantía económica (Nieto y Cárdenas, 2015).

Así, en estos 25 años de trayectoria del Método LEADER, en Extremadura se han invertido más de 119,7 millones de euros en turismo rural, un 22,5\% del total de las inver- 
siones, en más de 1.200 proyectos (19\% del total), que, aunque ha tenido una disminución porcentual en cuanto a los inicios de LEADER I y LEADER II en la década de los 90, se mantiene como una de las medidas con mayores inversiones en la ejecución de estos programas, solo siendo superada por las inversiones y proyectos en PYMES y Servicios (30,6\% de inversiones y $21,8 \%$ de proyectos).

Respecto a la eficacia, se observa que el número de proyectos medios ejecutados por superficie es 5,6 proyectos por $100 \mathrm{~km}^{2}$. Las comarcas con mejores resultados son territorios con una superficie relativamente pequeña, localizadas en las zonas de montaña del norte de la provincia cacereña como son Valle del Ambroz, Valle del Jerte, Hurdes, La Vera, Trasierra-Cáparra y Sierra de Gata. Los Grupos con municipios de mayor extensión, localizados en las áreas de regadío y de penillanura, presentan resultados menos óptimos, como Barros Oeste, Vegas Altas del Guadiana, Olivenza y Campiña Sur (tabla 5).

Al relacionar las inversiones con la población, se obtiene que la media es de 2,8 proyectos por 1.000 habitantes. Los mejores resultados los obtienen los mismos Grupos que en el análisis anterior, en comarcas con poca extensión pero también con escasa población, en los que se localiza el mayor número de municipios con menos de 2.000 habitantes. Siguen estando localizados en las montañas del Norte de Cáceres como Hurdes, Valle del Jerte, Valle del Ambroz, La Vera y Sierra de Gata. En el lado opuesto se sigue el mismo comportamiento, Grupos localizados en zonas de regadío, de penillanura y de secano de viñedo y olivo (Barros, Olivenza, Campo Arañuelo y Vegas del Guadiana).

En cuanto a la eficiencia de las inversiones, la capacidad de movilizar mayor volumen de efectivo, existen también notables diferencias territoriales. La media de Extremadura es 320.349 euros/ km² y 158.961 euros por 1.000 habitantes. Se localizan los mismos contrastes espaciales, las zonas de montaña del Norte de Cáceres son las que presentan mayores inversiones en turismo tanto por población como por superficie (los Grupos de Hurdes, Valle del Jerte, Valle del Ambroz, La Vera, Sierra de Gata y Trasierra-Cáparra) y las menores inversiones en las zonas de regadío (Vegas Altas del Guadiana, Campo Arañuelo, Miajadas-Trujillo) y en la penillanura (Campiña Sur, La Serena y La Siberia) y en las de secano productivo de olivar y viñedo (Barros - Oeste).

Siguiendo el método NADIR, desarrollado en la metodología, se obtienen las siguientes tipologías (figura 2):

- Grupos con índices altos, en las zonas de montaña del Norte de Cáceres (La Vera, Valle del Jerte, Trasierra-Cáparra, Hurdes, Sierra de Gata y MontánchezTamuja).

- Grupos con índices medios - altos y medios, en zonas de transición de montaña y penillanura (Valle del Alagón, Tajo-Salor-Almonte, Monfragüe y su entorno, Miajadas-Trujillo, Villuercas-Ibores, La Serena y Tentudía).

- Grupos con índices bajos, en las zonas de regadío de la provincia de Cáceres (Campo Arañuelo y Ambroz) y de la provincia de Badajoz (Vegas Altas, Lácara y Olivenza); de secano productivo de vid y olivo (Barros Oeste, Zafra-Río Bodión); y en zonas de transición de penillanura-montaña en el Sur de la provincia de Badajoz (Jérez- Sierra SO, La Serena y Campiña Sur). 


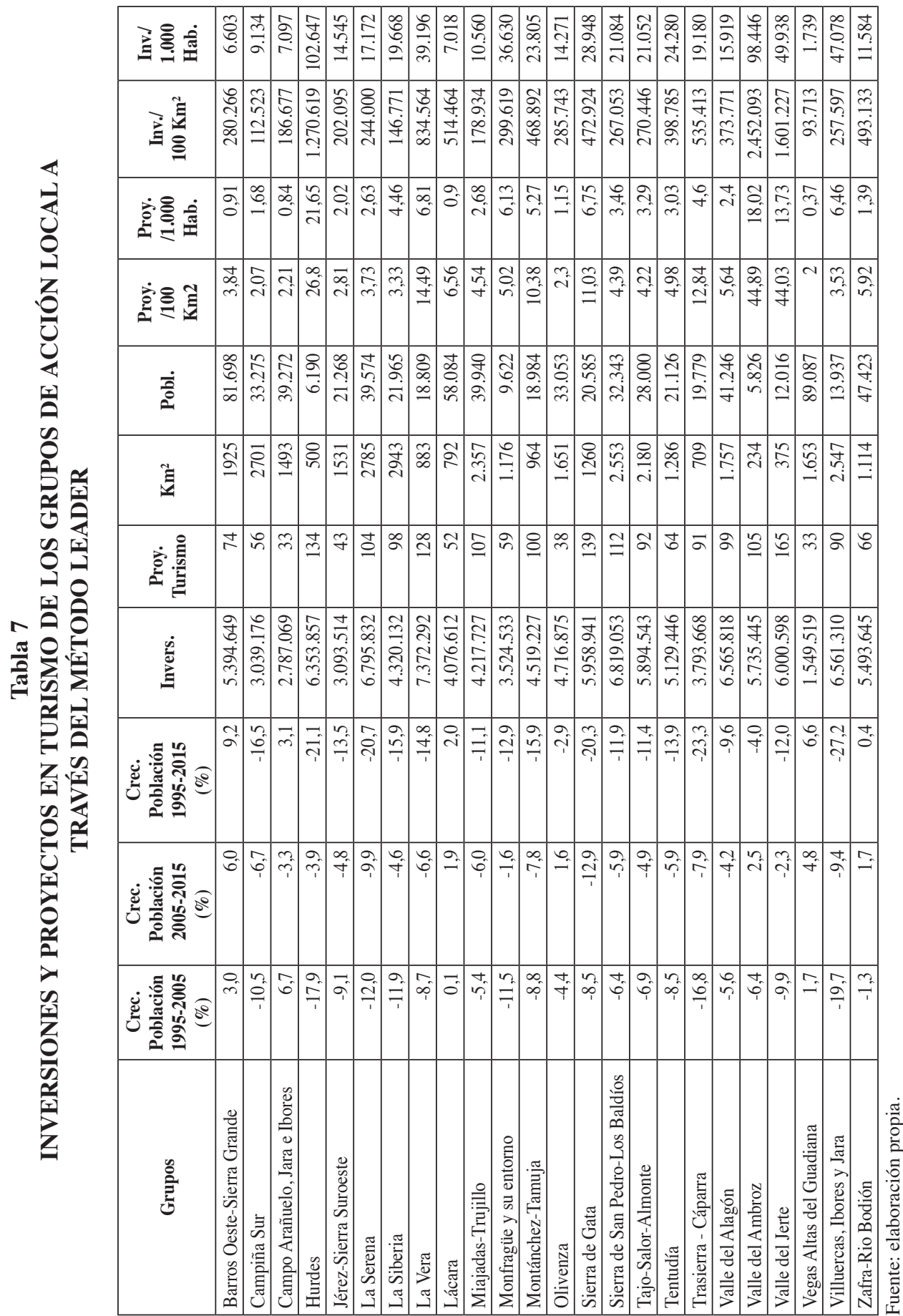




\section{Figura 2 \\ PUNTO IDEAL EN TURISMO Y CRECIMIENTO DE LA POBLACIÓN DEL MÉTODO LEADER}

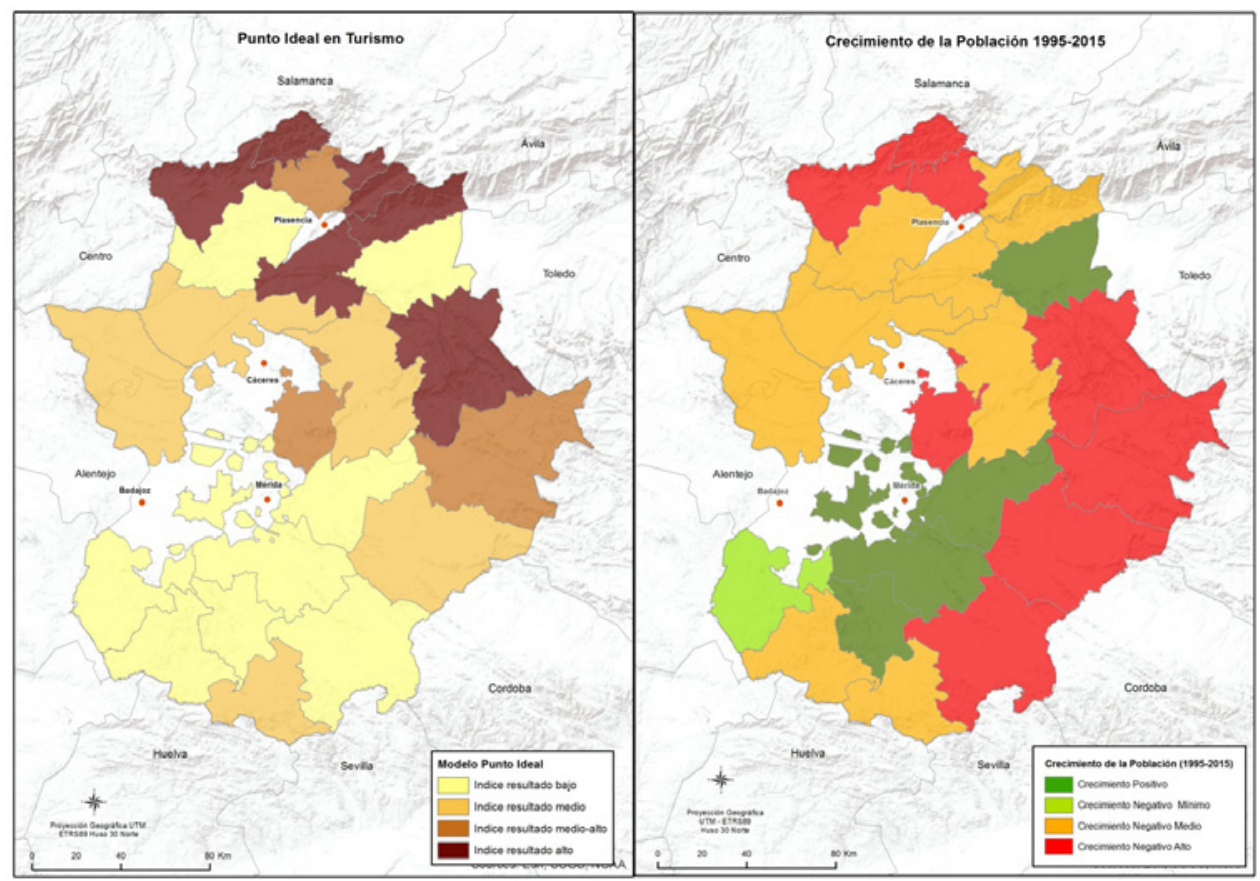

Fuente: elaboración propia.

Aquellas comarcas con mejores resultados de eficacia y eficiencia en turismo rural presentan a la vez los peores indicadores económicos y demográficos. En los demográficos, los Grupos del norte de Cáceres (Trasierra-Cáparra. Monfragüe, Hurdes, Sierra de Gata, Villuercas, Montánchez, La Vera) presentan un índice de vejez con tasas medias superiores al $30 \%$, en contraste con los más dinámicos de la región, con valores medios del 20\%, como es el caso de los Grupos de las Vegas del Guadiana y Barros (figura 3). También son los que siguen perdiendo grandes volúmenes de población desde la implantación del Método LEADER (tabla 7), añadiéndose los territorios de Tentudía, Jérez, Campiña o La Serena en la provincia pacense, aunque no estén tan envejecidos. Sólo han visto aumentar su población, durante el transcurrir de los distintos períodos, los Grupos de Campo Arañuelo, Olivenza, Lácara, Vegas Altas del Guadiana, Barros Oeste y Valle del Ambroz, localizados todos ellos en zonas de regadío o secano (con la excepción del Valle del Ambroz, que sin ser de regadío, ha logrado diversificar su economía con otras actividades, como la industria del mueble).

En el aspecto económico presentan resultados diferentes. El Índice de actividad económica y el PIB se ven incrementados en algunas comarcas rurales y poco dinámicas por localizarse en ellas las centrales hidroeléctricas y nucleares extremeñas (aunque estos 
rendimientos económicos tributan en regiones exteriores). Los peores resultados los siguen obteniendo las comarcas de las Hurdes, Trasierra-Cáparra, Sierra de Gata, Villuercas o Sierra de San Pedro (figura 3).

\section{Figura 3 \\ ÍNDICE DE ACTIVIDAD ECONÓMICA E ÍNDICE DE VEJEZ DE LOS GRU- POS DE ACCIÓN LOCAL EXTREMEÑOS}

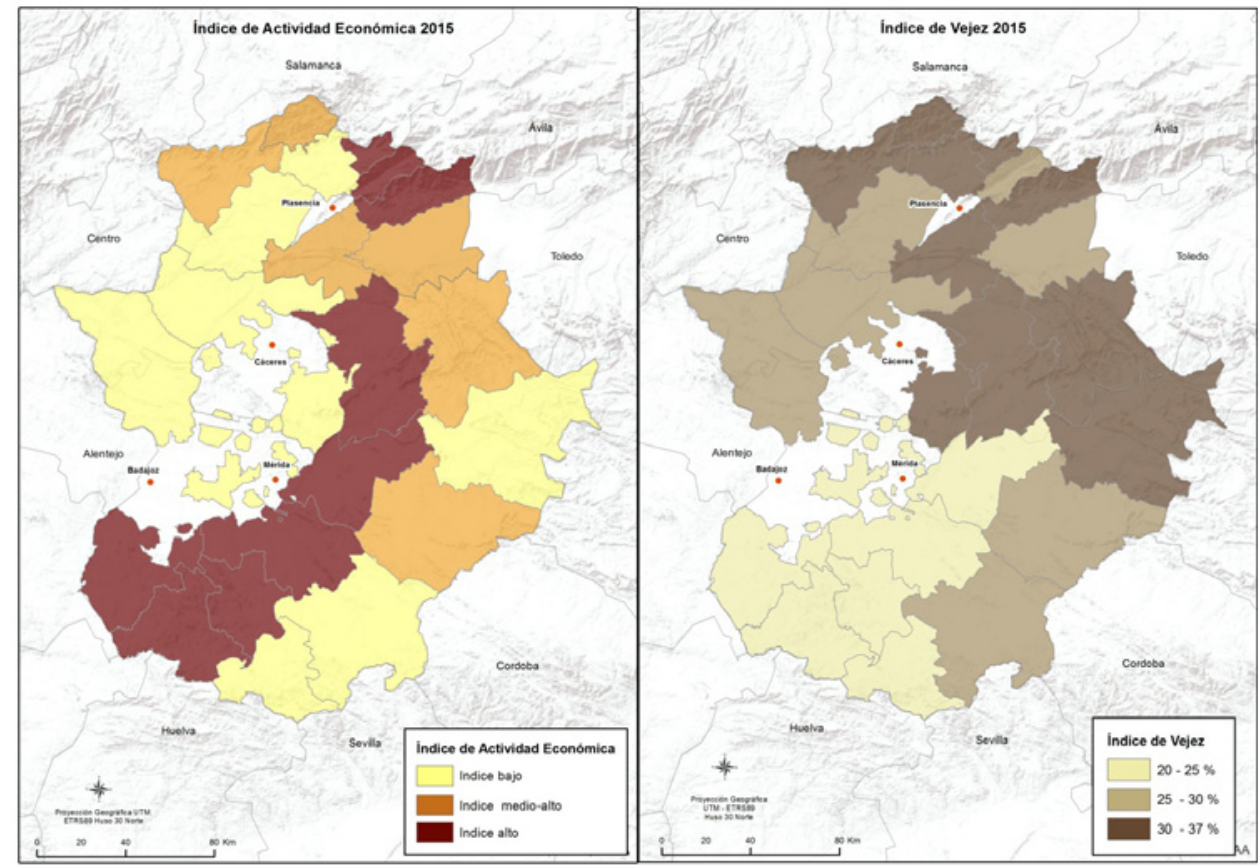

Fuente: elaboración propia.

Con la orientación de las inversiones hacia el turismo no se está logrando frenar la despoblación de estos espacios, debido a que la situación de partida es muy regresiva: la mayoría son municipios con menos de 2.000 habitantes, presentan altos índices de vejez y una actividad económica poco desarrollada por la inexistencia de un tejido empresarial joven y dinámico (figura 3), sin dejar de mencionar que las aportaciones económicas del Método LEADER son ínfimas si se comparan con otras ayudas como la PAC, el subsidio agrario, las inversiones llevadas a cabo en infraestructuras o equipamientos sanitarios y educativos con fondos FEDER, estatales o autonómicas. Es por ello que aun no son lo suficientemente cuantiosas, y por ende ambiciosas, como para lograr crear y establecer un tejido empresarial y dinámico basado en nuevas actividades, como el turismo, así como para provocar un cambio radical en las tendencias demográficas regresivas que desde hace décadas existen en Extremadura. 


\section{CONCLUSIONES}

Los espacios rurales europeos, desde mediados del siglo pasado, han sufrido un proceso de deterioro por profundas transformaciones económicas: las reestructuraciones que se realizan en el sector agrario evolucionando a una agricultura modernizada y competitiva; y sociales: la emigración de su población joven y sobre todo masculina hacia zonas urbanas, que desemboca en un proceso de feminización y envejecimiento de la población agraria. Por ello, surge una serie de políticas públicas diseñadas para lograr la diversificación de actividades en los espacios rurales y mejorar las rentas económicas y en consecuencia, mantener la población que ya no tendrá la necesidad de emigrar hacia espacios con mejores oportunidades laborales. Estas actuaciones se centran no sólo en una óptima explotación económica y sostenible del medio ambiente, de la agricultura y de la ganadería, sino también en introducir nuevas actividades como la agroindustria, nuevas empresas de comercialización o en el caso que nos ocupa, el turismo.

En este trabajo se ha analizado en la región extremeña, una región predominantemente rural (OCDE, 2004)7, una de las metodologías desarrolladas por la Unión Europea para conseguir la diversificación de actividades de sus zonas rurales, que es el Método LEADER, y más concretamente sus actuaciones en turismo y si éstas han logrado su objetivo primordial: el mantenimiento de la población, frenar la emigración y disminuir el envejecimiento.

Aunque estos programas en sus inicios no fueron diseñados en modo alguno como un programa de desarrollo turístico, han funcionado como impulsores de este sector en Extremadura, por el enorme peso de las medidas específicas de turismo rural en la gestión de LEADER y PRODER desde sus inicios en los años 90. Se han invertido casi 120 millones de Euros, un 22,5\% del total de las inversiones, con la puesta en marcha de más de 1.200 proyectos, un $12 \%$ del total de los mismos. También se han creado más de 7.800 nuevas plazas hoteleras y se han creado o mejorado más de 600 empresas.

Se ha comprobado que existe una reducción de los aportes de la medida de turismo desde LEADER I (1991-1994), tanto a nivel nacional como regional, pasando del 37\% de las inversiones en la primera etapa al 20,1\% en el último período ya finalizado (2007-2013).

Las normativas de estos programas de desarrollo y las recomendaciones de la Comisión Europea en sus evaluaciones han tendido en su evolución a una diversificación de las actividades, pero también es cierto que actuaciones de otras medidas, como potenciar los temas medioambientales, recuperación de productos locales o valorización de zonas naturales y culturales, están íntimamente relacionadas con reforzar el turismo rural. De este modo, sería recomendable que una vez se haya creado una oferta de alojamientos y restaurantes, se progrese creando ofertas integrales de turismo en las que se incluyan nuevas actividades de ocio, campañas de difusión, actividades culturales en museos o centros de interpretación, rutas de senderismo o empresas artesanas de comercialización de productos típicos de cada territorio.

7 La región es considerada "predominantemente rural" porque la proporción de población que se asienta en municipios con una densidad de población inferior a $150 \mathrm{hab} / \mathrm{km}^{2}$ (criterio de ruralidad) es superior al $50 \%$. 
A partir de los resultados obtenidos al analizar los proyectos financiados por los Grupos de Acción Local desde 1991, se comprueba que se ha creado una pequeña infraestructura turística en las zonas rurales, tanto en las zonas de montaña como en llanos o vegas, debido a que cada Grupo ha relacionado su oferta turística con una determinada estrategia: explotación de recursos naturales, culturales o históricos, creación de las distintas tipologías de alojamientos turísticos (casas rurales (237), hostales y hoteles (48), campings y albergues (33) o apartamentos rurales (62)). También se ha detectado que en los dos últimos períodos se han introducido nuevas tipologías de proyectos turísticos: sistemas de reservas con los que canalizar no sólo la oferta de alojamientos sino de otras actividades relacionadas con la estrategia de cada grupo, como es la explotación de recursos cinegéticos, rutas naturales, embalses y ríos; creación y promoción turística con folletos, campañas en medios de comunicación, páginas web, apertura de museos y centros de interpretación, de oficinas de turismo, etc. Además, destacar que se han creado numerosos puestos de trabajos nuevos o mantenido otros ya existentes.

En cuanto a la localización territorial de estas ayudas, se ha introducido una serie de indicadores (número de proyectos y de inversiones) que nos permite medir el impacto territorial al relacionarlos con la superficie comarcal y poblacional (indicadores de contexto) y se han normalizado sus resultados con los métodos estadísticos NADIR y Punto Ideal. Los mejores resultados en cuanto a inversiones y proyectos por población y superficie los localizamos en las zonas de montaña del norte de Cáceres, en Grupos como La Vera, Valle del Jerte, Trasierra-Cáparra, Hurdes, Sierra de Gata y Montánchez-Tamuja. Son Grupos localizados en zonas con gran riqueza paisajística (montañas, riberos, embalses,...) y un tejido empresarial menos desarrollado, y por ello han ejecutado mayor número de proyectos dedicados a la implantación de nuevos alojamientos o instalaciones relacionados con el turismo que a la mejora o implantación de nuevas empresas agrarias o de servicios, aunque hay que tener en cuenta que la mayoría de estos Grupos en las primeras etapas ejecutaron PRODER y este programa ha tenido una normativa más flexible que la de LEADER en la que no se obligaba a realizar las mismas inversiones en todas las medidas productivas, por lo que los GAL podían priorizar más en ciertos sectores, como es en este caso el turismo, al contar con ricos recursos naturales y no tener un tejido empresarial decidido a financiar proyectos en Pymes, servicios o revalorización de la producción agraria. Sin embargo, estas mayores inversiones por habitantes y por superficie en turismo no han logrado los resultados todavía necesarios para alcanzar los objetivos que se plantea el Método LEADER: mantener la población joven en las zonas rurales frenando los procesos emigratorios y disminuyendo el envejecimiento. Son estos Grupos los que peores resultados presentan en el Índice de vejez (con valores superiores al 30\%) y un crecimiento de la población negativo, debido sobre todo a sus altas tasas de mortalidad y mínimas de natalidad.

Aun así, no se puede dejar de reseñar que sin estas ayudas los efectos en las últimas décadas en los espacios rurales más envejecidos y con poco volumen de población (la mayoría con menos de 2.000 habitantes) habrían sido todavía más perjudiciales, porque acciones como el Método LEADER han permitido la creación de una identidad de comarca, lo cual también se ha explotado en muchos casos como recurso turístico, y la construcción de nuevos negocios como casas rurales, restaurantes, hoteles, apartamentos rurales,... que sin las aportaciones de los fondos públicos podrían no haberse llegado 
nunca a realizar por la tendencia más sedentaria de la población rural a invertir en nuevos negocios y por los riesgos de éxito que estos espacios presentan. No sólo se han ejecutado proyectos tradicionales, sino también otros más innovadores dedicados a nuevas ofertas de turismo, reseñados en párrafos anteriores, o a la rehabilitación del patrimonio natural y cultural o mejora de servicios a la población en adecuación de calles, depósitos de agua, accesos a recursos, etc.. Son proyectos que seguramente sin LEADER, por ser no productivos, no se habrían llevado a cabo.

Atendiendo a todos los resultados obtenidos y a las conclusiones extraídas, es necesario declarar que en el próximo período se debería ahondar en seguir implantando y mejorando una oferta integral de turismo en los espacios rurales con nuevos alojamientos, pero también con otras ofertas que permitan cada vez más mayores estancias de los turistas y que generen beneficios complementarios en otras empresas de productos agrarios, artesanos, de servicios a la población, etc., así como en aprovechar nuevas tendencias demandadas en turismo, como el agroturismo o turismo de aventura. Por último, no se puede olvidar el tema de la comercialización y el asociacionismo, asignaturas aún pendientes en este sector y que contribuirían para obtener mejores resultados.

\section{AGRADECIMIENTOS}

Agradecimientos a la Secretaría General de Ciencia, Tecnología e Innovación de la Junta de Extremadura por la concesión de la ayuda para la Formación del Personal Investigador predoctoral (PD12028), cofinanciada con fondos FSE (Fondo Social Europeo), con la que es posible la realización de este trabajo.

\section{BIBLIOGRAFÍA}

ACTUALIDAD LEADER (1998): «El LEADER I en España. Una experiencia innovadora». Actualidad LEADER-Revista de Desarrollo Rural, Unidad Española del Observatorio Europeo LEADER, $\mathrm{n}^{\circ} 1$, pp. 16-20.

ALARIO TRIGUEROS, M. y BARAJA RODRÍGUEZ, E. (2006): «Políticas públicas de desarrollo rural en Castilla y León. ¿Sostenibilidad consciente o falta de opciones en LEADER II?». Boletín de la Asociación de Geógrafos Españoles, nº 41, pp. 267-294

ALBERDI COLLANTES, J.C. (2004): «Colaboración interinstitucional en el desarrollo rural: Aciertos y fracasos de la ley de desarrollo rural del País Vasco». Boletín de la Asociación de Geógrafos Españoles, n 38, pp. 131-151.

ANDRÉS SARASA, J.L. y ESPEJO MARÍN, C. (2006): «Interacción mito religioso/producto turístico en la imagen de la ciudad: Caravaca de la Cruz (Murcia)». Cuadernos de Turismo, $\mathrm{n}^{\mathrm{o}} 18$, pp. 7-61.

BLANCO PORTILLO, R. y BENAYAS DEL ALAMO, J. (1994): «El turismo como motor de desarrollo rural. Análisis de los proyectos de turismo subvencionados por LEADER I». Revista de Estudios Agrosociales, n 169, pp. 119-147.

CANDELA HIDALGO, A.R.; GARCÍA CARRETERO, M.. y SUCH CLIMENT, M.Paz (1995): «La potenciación del turismo rural a través del programa LEADER: La Montaña de Alicante». Investigaciones Geográficas, n ${ }^{14}$, pp. 77-98. 
CÁNOVES, G., VILLARINO, M., y HERRERA, L. (2006): «Políticas públicas, turismo rural y sostenibilidad: difícil equilibrio». Boletín de la Asociación de Geógrafos Españoles, $\mathrm{n}^{\circ}$ 41, pp. 199-217.

CARVALHO, P. y FERNANDES, J. L. (2001): «Iniciativas de desenvolvimiento local no espaço rural portugués». En Caetano, L. Território, inovaçao e trajectorias de desenvolvimiento. Centro de Estudios Geográficos da Fluc. Coimbra. pp. 241-272.

CEBRIÁN ABELLÁN, A. (2003): «Génesis, Método y territorio del desarrollo rural con enfoque local». Papeles de Geografía, n 38 , pp. 61-76.

CEJUDO GARCÍA, E. y NAVARRO VALVERDE, F. A. (2009): «La inversión en los programas de desarrollo rural. Su reparto territorial en la provincia de Granada». Anales de Geografia de la Universidad Complutense, vol. 29, n 2, pp. 37-64.

COMISIÓN DE LAS COMUNIDADES EUROPEAS (1988): El futuro del mundo rural. Comunicación de la Comisión al Parlamento Europeo y al Consejo el 29 de julio de 1988. (COM (88)501 final).

COMISIÓN EUROPEA (1997): Agenda 2000. For a stronger and wider Union. Bruselas, COMISIÓN EUROPEA. (1999): Estrategia Territorial Europea: Hacia un desarrollo equilibrado y sostenible del territorio de la Unión Europea. Luxemburgo: Oficina de Publicaciones Oficiales de las Comunidades Europeas.

CONFERENCIA EUROPEA DE DESARROLLO RURAL (1996): La Declaración de Cork: "Por un paisaje rural vivo". Cork (Irlanda, 7 al 9 de noviembre de 1996.

DELGADO VIÑAS, C. y DE LA FUENTE ROYANO, M. T. (2000): «Las estrategias de desarrollo rural: una valoración del PRODER en Cantabria». En Actas del X Coloquio de Geografía Rural. Asociación de Geógrafos Españoles. Grupo de Geografía Rural. Lleida. Páginas 623-634.

ESPARCIA PÉREZ, J. (2012): «Evolución reciente, situación actual y perspectivas futuras en el desarrollo rural en España y en la UE». Revue Marocaine d'Administration Locale et de Développement (REMALD), $\mathrm{n}^{\circ} 79$.

GARCÍA HERNÁNDEZ, M. y DE LA CALLE VAQUERO, M. (2006): «Turismo en el medio rural: conformación y evolución de un sector productivo en plena transformación. El caso del valle del Tiétar (Ávila)». Cuadernos de Turismo, n 17, pp. 75-101.

GARCÍA MARÍN, R. (2011): «Turismo y desarrollo rural en la comarca del noroeste de la región de Murcia: los programas europeos LEADER». Cuadernos de Turismo, $\mathrm{n}^{\circ}$ 27, pp. 419-435.

GARCÍA MARÍN, R. y CEBRIÁN ABELLÁN, A. (2008): «El modelo LEADER, base del ordenamiento rural en la Unión Europea». Ágora, Santa Cruz do Sul. V. 14, n. 1, pp. 22-48.

GARCÍA PAREDES, C. y NIETO MASOT, A. (2015): «La organización de la atención sociosanitaria a las personas mayores en Extremadura». Investigaciones Geográficas, $\mathrm{n}^{\circ} 63$, pp. 161-178.

GIL DE ARRIBA, C. (1999): «Programas europeos y desarrollo rural en Cantabria. Actuaciones y perspectivas». Polígonos, $\mathrm{n}^{\circ}$ 8, pp. 39-51.

GÓMEZ, M.A, MONDÉJAR, J.A., MONDÉJAR, J. y MONSALVE, F. (2007): «El turismo rural en los programas de desarrollo en Castilla-La Mancha». En Blanquer, D. (Eds). Turismo en espacios rurales. Tirant Lo Blanch. Valencia. 
GONZÁLEZ CABRERA, A. (2004): «La políticas de desarrollo rural en España, un análisis crítico». Documentación Social, n 133, pp. 77-103.

GONZÁLEZ REGIDOR, J. G. (2000): El futuro del medio rural en España. Madrid, Consejo Económico y Social, 187 pp.

GUTIÉRREZ GONZÁLEZ, S. (2000): «Balance de la aplicación de la iniciativa europea de desarrollo rural LEADER en Campoo (Cantabria)». Actas del X Coloquio de Geografía Rural. Asociación de Geógrafos Españoles. Grupo de Geografía Rural. Lleida. Páginas 669-678.

HERNÁNDEZ HERNÁNDEZ, M. (1998): «Balance de las políticas de desarrollo rural en la Comunidad Valenciana (1991-2006)». Investigaciones Geográficas, n 45. pp. 93-119.

HERNÁNDEZ HERNÁNDEZ, M., MOLTÓ MANTERO, E. A. y RICO AMORÓS, A.M. (2008): «Las actividades turístico-residenciales en las montañas valencianas». Ería, ${ }^{\circ}$ 75, pp. 77-97.

IAKDVIDDU, D., KDUTSDURIS, A. y PARTALLDDU, M. (2002): «The Development of Rural Tourism in Greece, Through the Initiative LEADER II: the Case of Northern and Central Chalkidiki». A Mediterranean Journal of Economics, Agriculture and Environment. New Medit. Journal, vol. 1, no 4, pp. 35-38.

LOSCERTALES PALOMAR, B. (1999): «El turismo rural como forma de desarrollo sostenible. El caso de Aragón». Geographicalia, n 37, pp. 123-138.

MAJORAL MOLINÉ, R. y SÁNCHEZ AGUILERA, D. (2001): «Assimetrías territoriais e áreas marginais em Espanha». En Caetano, L. Território, inovaçao e trajectorias de desenvolvimiento. Centro de Estudios Geográficos da Fluc. Coimbra. pp. 215-239.

MAPA. (2004): «El estado de la cooperación en LEADER +. Mucho en común». Actualidad LEADER. Revista de desarrollo rural, $\mathrm{n}^{\circ} 26$.

MÉNDEZ GUTIÉRREZ DEL VALLE, R. y CARAVACA BARROSO, I. (1996): Organización industrial y territorio. Madrid, Síntesis.

MONDÉJAR JIMÉNEZ, J.A., MONDÉJAR JIMÉNEZ, J. y VARGAS VARGAS, M. (2008): «Análisis del turismo cultural en Castilla-La Mancha (España). El impacto de los programas europeos de desarrollo rural LEADER y PRODER». Estudios y Perspectivas en Turismo, vol. 17, $\mathrm{n}^{\circ}$ 4, pp. 359-370.

MORÁN RODRÍGUEZ, M.A. y SOTELO NAVALPOTRO, J.A. (2002): «El turismo rural y LEADER+ en la sierra norte madrileña». Anales de Geografía de la Universidad Complutense, vol. extraordinario, pp. 471-481.

NIETO MASOT, A. y GURRÍA GASCÓN, J.L. (2005): «Análisis de la población de los programas de desarrollo rural en Extremadura mediante sistemas de Información Geográfica». Cuadernos Geográficos, nº 36, pp. 479-495.

NIETO MASOT, A. y GURRÍA GASCÓN, J.L. (2010): «El modelo rural y el impacto de los programas LEADER y PRODER en Extremadura (Propuesta metodológica)». Scripta Nova, vol. 14, $\mathrm{n}^{\circ} 340$.

NIETO MASOT, A. y CÁRDENAS ALONSO, G. (2015): «El Método LEADER como política de desarrollo rural en Extremadura en los último 20 años (1991-2013)». Boletín de la Asociación de Geógrafos Españoles, n 69, pp. 139-162. 
OCDE, (2004): Placed-based policies for rural development Extremadura, Spain (case study). 6th Session held at the OECD Headquarters in Paris on 7 December 2004.

PÉREZ FRA, M.M. y LÓPEZ IGLESIAS, E. (2005): «La contribución del turismo a la diversificación de actividades en un espacio rural periférico. Análisis del impacto de la Iniciativa LEADER en Galicia». Estudios Agrosociales y Pesqueros, $\mathrm{n}^{\circ} 206$, pp. 111-135.

PILLET CAPDEPÓN, F. (2008): «Del turismo rural a la plurifuncionalidad en los territorios LEADER y PRODER de Castilla-La Mancha», en Cebrián, Francisco. (Coord.): Turismo rural y desarrollo local. Cuenca, Universidad de Castilla-La Mancha, pp. 187-198.

REIS, J. (1998): «Interior, desenvolvimiento e território». Perspectivas de desenvolvimiento do interior. INCM. Lisboa.

RUÍZ BUDRÍA, E., FRUTOS MEJÍAS, L.M. y CLIMENT LÓPEZ, E. (2000): «La iniciativa comunitaria LEADER II y el desarrollo rural: el caso de Aragón». Geographicalia, $\mathrm{n}^{\mathrm{o}}$ 38, pp. 71-84.

TOLEDANO GARRIDO, N. y GESSA PERERA, A. (2002): «El turismo rural en la provincia de Huelva. Un análisis de las nuevas iniciativas creadas al amparo de los programas LEADER II y PRODER». Revista de Desarrollo Rural y Cooperativismo Agrario, $\mathrm{n}^{\circ}$ 6, pp. 107-121.

TROITIÑO VINUESA, M.A. (1995): «El turismo en las ciudades históricas». Polígonos, $\mathrm{n}^{\circ}$ 5. pp. 49-65.

VARGAS VARGAS, M. y MONDÉJAR JIMÉNEZ, J. A. (2006): «Análisis de la inversión de los Fondos Europeos para el Desarrollo rural en Castilla-La Mancha». Revista Económica de Castilla-La Mancha, $\mathrm{n}^{\circ}$ 9, pp. 189-238.

ZAPATERO ZAPATERO, J. y SÁNCHEZ MUÑOZ, M.J. (1999): «Instrumentos específicos para el desarrollo rural integrado: la Iniciativa Comunitaria LEADER y el Programa Operativo PRODER». Polígonos, nº 8, pp. 21-38. 